\title{
Effects of Chemical Structure Changes on Thermal, Mechanical, and Crystalline Properties of Rigid Rod Epoxy Resins
}

\author{
W.-F. A. SU, K. C. CHEN, S. Y. TSENG \\ Institute of Materials Science and Engineering, National Taiwan University, Taipei, Taiwan, Republic of China
}

Received 12 May 1999; accepted 10 December 1999

\begin{abstract}
Effects of chemical structure changes on the thermal, mechanical, and crystalline properties of rigid rod epoxy resins have been studied for azomethine epoxy, biphenol epoxy, and tetramethyl biphenol epoxy. Rigid rod epoxies have exhibited better properties than those of the flexible bisphenol A epoxy. The chemical structures of both rigid rod epoxy and curing agent control the properties of cured rigid rod epoxies. When a flexible curing agent (methyl cyclohexane 1,2-dicarboxylic anhydride) was used, the chemical structure of rigid rod epoxy has dominated effects on the properties. Thus, the azomethine epoxy has shown the best thermal and mechanical properties among three rigid rod epoxies. While a rigid curing agent (sulfanilamide) was used, the physical properties of cured epoxies are not only dependent on the chemical structures of epoxies but also on the ease of formation of ordered network. Among the cured rigid rod epoxies, only the biphenol epoxy cured by sulfanilamide exhibits a liquid crystalline network. It has the highest glass transition temperature $\left(219^{\circ} \mathrm{C}\right)$ and the lowest coefficient of thermal expansion $\left(20.8 \mu \mathrm{m} / \mathrm{m}^{\circ} \mathrm{C}\right)$. However, the most thermal stable system is azomethine epoxy cured with sulfanilamide. It has a weight loss (39\%) at $450^{\circ} \mathrm{C}$. Their excellent thermal and mechanical properties of rigid rod epoxies are useful in composites, printed wiring boards, integrated circuit encapsulations, etc. (๑) $2000 \mathrm{John}$ Wiley \& Sons, Inc. J Appl Polym Sci 78: 446-451, 2000
\end{abstract}

Key words: liquid crystalline; epoxy; biphenol; azomethine; rigid rod

\section{INTRODUCTION}

Polymers with aromatic rigid rod moiety are known to have exceptional thermal and mechanical properties. They also exhibit liquid crystalline behavior. ${ }^{1,2}$ The liquid crystalline polymers were commercialized in late 1980. However, their usage has not been widely accepted because of the anisotropic properties and the difficulty of processing (e.g., high melting temperature, high pro-

Correspondence to: W.-F. A. Su. (suwf@ccms.ntu.edu.tw).

Contract grant sponsor: National Science Council of Republic of China; contract grant number: NSC87-2216E-002-004.

Journal of Applied Polymer Science, Vol. 78, 446-451 (2000)

(c) 2000 John Wiley \& Sons, Inc. cessing pressure, low solubility in common solvents). Recently, epoxy resins containing rigid rod structure have been synthesized as a new class of high performance polymers. ${ }^{3-5}$ Most of rigid rod epoxies exhibit liquid crystalline behavior. Their crosslinking capability of the oxirane ring reduces their anisotropic properties. The uncured epoxies are either monomers or oligomers which have low melting points and can be easily processed.

The amine or anhydride cured rigid rod epoxies have shown improved thermal, mechanical, and electrical properties as compared with bisphenol A epoxy cured by the same type of curing agents. For instance, Ochi et al. ${ }^{6}$ showed that biphenol epoxy cured with phenol novolak and aromatic diamine exhibit increased lap shear strength, adhesive strength, tensile strength, and fracture 
toughness. $\mathrm{We}^{7}$ cured the biphenol epoxy with trimellitic anhydride and diamino diphenylsulfone, respectively. The cured resins exhibited an improved thermal and electrical properties. Sue et al. ${ }^{8}$ obtained a high fracture toughness prop$\operatorname{erty}\left(G_{\mathrm{IC}}=580 \mathrm{JM}^{-2}\right.$ as compared with $G_{\mathrm{IC}}=180$ $\mathrm{JM}^{-2}$ for bisphenol A system ) and high tensile modulus when the $\alpha$-methyl stilbene epoxy was cured with sulfanilamide. Muller et al. ${ }^{9}$ reported an increased tensile modulus (3070 MPa vs. 2346 $\mathrm{MPa}$ for bisphenol A epoxy) when dihydroxy phenyl benzoate epoxy was cured with a hexahydrophthalic anhydride. The properties of cured azomethine epoxy have not been widely investigated. Mikroyannidis ${ }^{10-12}$ reported a high char yield $(47 \%)$ when a diaminodiphenylsulfone cured azomethine epoxy was heated to $800^{\circ} \mathrm{C}$ in nitrogen.

We studied the thermal, mechanical, and crystalline properties of azomethine epoxy cured with sulfanilamide and methyl cyclohexane 1,2-dicarboxylic anhydride, respectively. The choice of rigid sulfanilamide curing agent was due to different reactivity of amino and amide groups toward the epoxy ring that helped the formation of highly ordered network structure. ${ }^{13}$ The selection of flexible methyl cyclohexane 1,2-dicarboxylic anhydride curing agent was due to this anhydride cured epoxy exhibiting good electrical properties. ${ }^{14}$ The study was performed in parallel with two other rigid rod epoxies: biphenol epoxy and tetramethyl biphenol epoxy, and a flexible bisphenol A epoxy. The effects of chemical structure changes on the properties of epoxies cured with the same type of curing agents can be investigated. The cured samples were characterized by differential scanning calorimetry (DSC), thermal gravimetric analysis (TGA), dynamic mechanical analysis (DMA), thermal mechanical analysis (TMA), and X-ray diffraction. The results are summarized and discussed in the following sections.

\section{EXPERIMENTAL}

\section{Materials}

Four epoxies and two curing agents were used. Their chemical structures are shown in Figure 1.

Biphenol epoxy [4,4'-bis(2,3-epoxypropoxy)biphenyl] (BP) was synthesized according to Su's procedure $^{7}$ with modification. Ten grams of $4,4^{\prime}$ dihydroxybiphenyl, $0.373 \mathrm{~g}$ of benzyl trimethyl ammonium bromide, and $85 \mathrm{~mL}$ of epichlorohy-

\section{Azomethine Linkage Epoxy Resin (AM)}

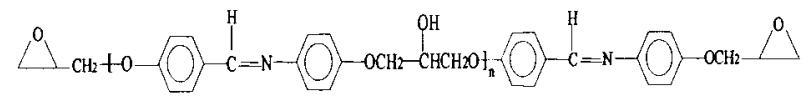

Biphenol Epoxy Resin (BP)

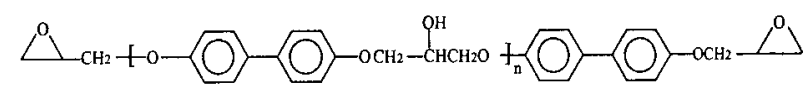

Tetramethyl Biphenyl Epoxy Resin (TMBP)

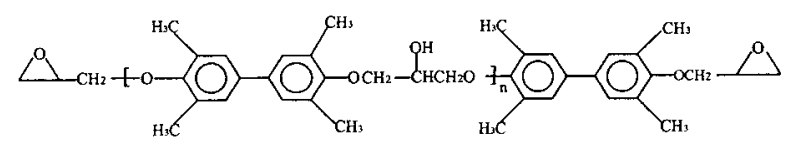

Diglycidyl Ether of Bisphenol A (DGEBA)

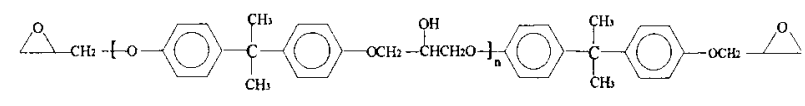

Methyl cyclohexane-1,2-dicarboxylic Anhydride (MCHDA) (mixture of isomers)

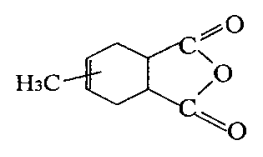

Sulfanilamide (SAA)

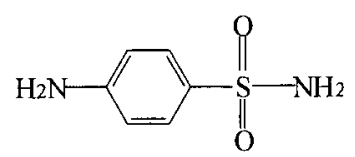

Figure 1 Chemical structures of epoxy resins and curing agents.

drin were placed in a $250-\mathrm{mL}$ three-neck flask equipped with a reflux condenser. The mixture was refluxed for $40 \mathrm{~min}$. A $28.64 \mathrm{~g}$ of $15 \% \mathrm{NaOH}$ aqueous solution was added into the mixture dropwise over a period of $3 \mathrm{~h}$ under reflux. The reaction was performed an additional hour after the addition at room temperature. The excess epichlorohydrin was removed by a vacuum distillation. The product was washed with water twice and methanol once. A white powder was obtained with a melting point of $155-156^{\circ} \mathrm{C}$, yield $94 \%$. The 
chemical structure of the product was identified as biphenol epoxy using Fourier transform infrared (Nicolet Magna-IR 550), FTNMR (Bruker, DMX-200), mass spectrum (Finnigan MAT 95S), and elemental analysis (Perkin-Elmer EA 2400). The epoxy equivalent of the product was determined by titration to be 160.76 (theoretical 149.08). Smectic liquid crystalline phase in the range of $128-153^{\circ} \mathrm{C}$ was observed using DSC (DuPont 9900 Series 910 DSC) and polarized microscope.

Azomethine epoxy [4,4'-bis(2,3-epoxypropoxy)benzylideneaniline] (AM) was synthesized according to the procedure of Mormann et al. ${ }^{15}$ A 44.38 $\mathrm{g}$ of $4,4^{\prime}$-dihydroxy benzylidene aniline and 490 $\mathrm{mL}$ of epichlorohydrin were placed in a $1 \mathrm{~L}$ threeneck flask equipped with a Dean-Stark trap and a condenser. The reaction mixture was stirred at $65-70^{\circ} \mathrm{C}$ until a yellow solution was obtained. Then, $0.24 \mathrm{~g}$ of benzyl trimethyl ammonium bromide was added and stirred for $30 \mathrm{~min}$. A $37.05 \mathrm{~g}$ of $45 \%$ aqueous $\mathrm{NaOH}$ was added dropwise over a period of $6 \mathrm{~h}$ at $65-70^{\circ} \mathrm{C}$ under reduced pressure. The by-product of salt was filtered out, the excess epichlorohydrin was removed at $60^{\circ} \mathrm{C}$ under reduced pressure. The product was precipitated by the addition of $450 \mathrm{~mL}$ of methanol. The product was collected by filtration and dried at $35^{\circ} \mathrm{C}$ under vacuum for $24 \mathrm{~h}$. A pink powder was obtained with a melting point of $128-129^{\circ} \mathrm{C}$ and $48 \%$ yield. The chemical structure of the product was identified as biphenol epoxy using Fourier transform infrared, FTNMR, Mass spectrum, and elemental analysis. The epoxy equivalent of the product was determined by titration to be 171.97 (theoretical 162.58). Nematic liquid crystalline phase in the range of $120-127^{\circ} \mathrm{C}$ was observed using DSC and polarized microscope.

Tetramethyl biphenol epoxy (TMBP) was supplied by Shell Chemical Company with a trade name of RSS1407 and an epoxy equivalent of 185 . The bisphenol A epoxy (DGEBA) was supplied by Dow Chemical Company with a trade name of DER 331 and an equivalent epoxy weight of 186 .

Methyl cyclohexane-1,2-dicarboxylic anhydride (MCHDA) and sulfanilamide (SAA) were purchased from Tokyo Industrial Chemical Company.

\section{Curing of Epoxy Resins}

The epoxy resin was melt mixed with a stoichiometric amount of curing agent. When an anhydride curing agent was used, a $1 \%$ by weight of 1-methyl imidazole catalyst was used. The 1-methyl imidazole catalyst was supplied by Vanderbilt Chemical Company. Eight samples were prepared with the composition (epoxy/curing agent) of: 1. DGEBA/MCHDA, 2. TMBP/MCHDA, 3. BP/MCHDA, 4. AM/MCHDA, 5. DGEBA/SAA, 6. TMBP/SAA, 7. BP/SAA, and 8. AM/SAA. The samples were cured according to the schedule of: 1. DGEBA/MCHDA: $175^{\circ} \mathrm{C} / 4 \mathrm{~h} ; 2$. TMBP/ MCHDA: $175^{\circ} \mathrm{C} / 4 \mathrm{~h}$; 3 . BP/MCHDA: $140^{\circ} \mathrm{C} / 4 \mathrm{~h}$ plus $180^{\circ} \mathrm{C} / 4 \mathrm{~h} ; 4$. AM/MCHDA: $110^{\circ} \mathrm{C} / 2 \mathrm{~h}$ plus $170^{\circ} \mathrm{C} / 4 \mathrm{~h}$; 5. DGEBA/SAA: $175^{\circ} \mathrm{C} / 24 \mathrm{~h} ; 6$. TMBP/ SAA: $175^{\circ} \mathrm{C} / 16 \mathrm{~h}$ plus $225^{\circ} \mathrm{C} / 4 \mathrm{~h} ; 7$. BP/SAA: $125^{\circ} \mathrm{C} / 16 \mathrm{~h}$ plus $200^{\circ} \mathrm{C} / 8 \mathrm{~h}$; and 8 . AM/SAA: $125^{\circ} \mathrm{C} / 16 \mathrm{~h}$ plus $175^{\circ} \mathrm{C} / 8 \mathrm{~h}$. The curing schedule and the degree of curing were determined by DSC. All the samples were fully cured as they showed no exothermic peaks of heat reaction in the DSC measurements.

\section{Measurement}

The DuPont 9900 Series, Model 954 TGA was used to evaluate the thermal decomposition temperature and thermal stability of the cured sample. A 5 to $15 \mathrm{mg}$ of sample was heated from room temperature to $500^{\circ} \mathrm{C}$ at $10^{\circ} \mathrm{C} / \mathrm{min}$ in nitrogen. The DuPont 9900 Series, Model 910 DSC was used to evaluate the rate and extent of curing of epoxy resin. A sample 5 to $10 \mathrm{mg}$ was heated at $10^{\circ} \mathrm{C} / \mathrm{min}$ from room temperature to $250^{\circ} \mathrm{C}$ in nitrogen. The DuPont 9900 series, Model 983DMA was used to study the mechanical properties of epoxy resin upon heating. The sample was heated from room temperature to $275^{\circ} \mathrm{C}$ at $2^{\circ} \mathrm{C} / \mathrm{min}$ in nitrogen, at $1 \mathrm{~Hz}$ frequency and 0.4-mm magnitude of vibration. The DuPont 990 series, Model 943 TMA was used to study the thermal expansion coefficient of epoxy resin. The sample was heated at $10^{\circ} \mathrm{C} / \mathrm{min}$ from room temperature to $230^{\circ} \mathrm{C}$ in air using a flat probe. The X-ray diffraction was obtained from Rigaku D/Max-VIII instrument at $2 \% \mathrm{~min}, 3$ to $30^{\circ}$ at $40 \mathrm{KV}, 30 \mathrm{~mA}$.

\section{Molecular Modeling}

The chain length of rigid rod moiety of epoxy resins was calculated by semi-empirical AM1 method using Hyper Chem 5 Molecular Modeling Program.

\section{RESULTS AND DISCUSSION}

A highly ordered epoxy resin is expected to have better thermal and mechanical properties than a 
Table I List of Glass Transition Temperatures of Amine and Anhydride Cured Epoxies

\begin{tabular}{lccc}
\hline & DSC & DMA & TMA \\
Epoxy Network & $T_{g}\left({ }^{\circ} \mathrm{C}\right)$ & $T_{g}\left({ }^{\circ} \mathrm{C}\right)$ & $T_{g}\left({ }^{\circ} \mathrm{C}\right)$ \\
\hline DGEBA/MCHDA & - & 74 & 58 \\
TMBP/MCHDA & 95 & 102 & 78 \\
BP/MCHDA & - & 103 & 88 \\
AM/MCHDA & - & 131 & 109 \\
DGEBA/SAA & 138 & 152 & 141 \\
TMBP/SAA & - & 185,201 & 167 \\
BP/SAA & - & 219 & 200 \\
AM/SAA & - & 217 & 201 \\
\hline
\end{tabular}

nonordered epoxy resin. From the molecular modeling calculation, we obtained the chain length of rigid rod moiety $-\mathrm{C}_{6} \mathrm{H}_{5}-\mathrm{N}=\mathrm{CH}-\mathrm{C}_{6} \mathrm{H}_{5}-(9.22$ $\AA$ ) of $\mathrm{AM}$ is longer than the chain length of rigid rod moiety $-\mathrm{C}_{6} \mathrm{H}_{5}-\mathrm{C}_{6} \mathrm{H}_{5}-(7.06 \AA)$ of BP. The $-\mathrm{N}=\mathrm{CH}-$ chain of azomethine epoxy could form hydrogen bonds with either curing agents MCHDA or SAA. The primary long chain rigid structure and possible secondary hydrogen bonding structure of azomethine epoxy would make the epoxy exhibit better thermal and mechanical properties than biphenol epoxy. TMBP has bulky four methyl groups substituted on the biphenyl rigid moiety that decreases the ordering structure of biphenol epoxy. Thus, the performance of thermal and mechanical properties of three rigid rod epoxies are expected to be in the decreasing order of azomethine epoxy $>$ biphenol epoxy $>$ tetramethyl biphenol epoxy. Epoxy cured with rigid SAA curing agent is also expected to have better thermal and mechanical properties than epoxy cured with a flexible MCHDA curing agent.

The thermal properties of cured epoxies were studied by DSC, DMA, TMA, and TGA. The glass transition temperatures $\left(T_{g}\right)$ of cured samples were measured by using DSC, DMA, and TMA. The results are summarized in the Table I. The DSC method is not very sensitive in detecting the glass transition of crosslinked polymer due to the small conformational changes in crosslinked polymer upon heating. There are only two samples: TMBP/MCHDA and DGEBA/SAA, which showed glass transition in DSC. The bulky tetramethyl substitution on the biphenol epoxy and a flexible bisphenol A chain in the bisphenol A epoxy may render crosslinked network less packed than other epoxy networks, so their $T_{g}$ could be observed by DSC. The DMA $T_{g}$ was obtained by dividing loss modulus over storage modulus (loss tangent). The value is about $20^{\circ} \mathrm{C}$ higher than the
$T_{g}$ obtained from the TMA method. However, three methods show the expected performance variations for all eight samples. Aromatic amine (SAA) cured samples have higher $T_{g}$ than those of the cyclic aliphatic anhydride (MCHDA) cured sample, because the rigid aromatic structure is more thermal stable than that of the cyclic aliphatic structure. The amine curing agent also gives a higher ordered epoxy network than that of anhydride curing agent. The $T_{g}$ differences between anhydride cured $\mathrm{AM}$ and $\mathrm{BP}$ is about $28^{\circ} \mathrm{C}$ but the $T_{g}$ differences between SAA cured AM and $\mathrm{BP}$ is only about $2^{\circ} \mathrm{C}$. The $-\mathrm{N}=\mathrm{CH}-$ bonding in the azomethine epoxy may form a more highly ordered structure in anhydride cured samples than in the amine cured samples.

Figures 2 and 3 show the curves of storage modulus versus temperature of anhydride cured and amine cured samples, respectively. The performance of the storage modulus of tested epoxies is in a decrease order of: $\mathrm{AM}>\mathrm{BP}>\mathrm{TMBP}$ $>$ DGEBA. The amine cured epoxies exhibit a higher storage modulus than that of anhydride cured epoxies because of the higher functionality of amine that gives a higher crosslinking density.

Table II lists coefficient of thermal expansion (CTE) of amine and anhydride cured epoxies. The epoxies cured with rigid sulfanilamide have a lower CTE than do the epoxies cured with flexible anhydride MCHDA as expected. However, the CTE changes before and after $T_{g}$ of amine cured epoxies are larger than those of anhydride cured epoxies. The amine cured epoxies may have a higher order network arrangement than do anhydride cured epoxies below $T_{g}$. Above $T_{g}$, the de-

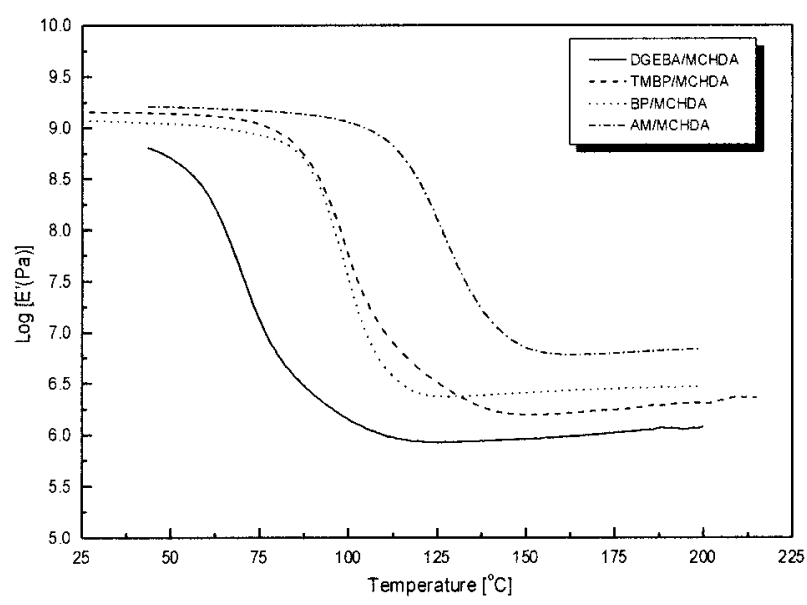

Figure 2 Plots of storage modulus versus temperature of methyl cyclohexane 1,2-dicarboxylic anhydrides cured epoxy resins. 


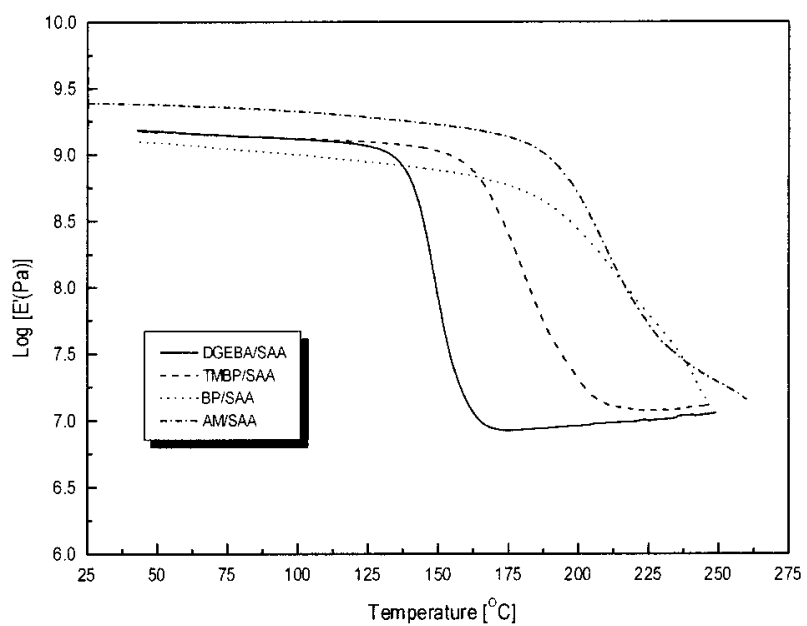

Figure 3 Plots of storage modulus versus temperature of sulfanilamide cured epoxy resins.

gree of freedom is greatly increased, thus the CTE increases. A lower CTE was observed for epoxies containing rigid rod main chain regardless of curing agents, which may also be due to their high ordering of the network. It is interesting to see an extremely low $\alpha_{1}$ (CTE before $T_{g}$ ) for the BP/SAA system that is in the same range of CTE of the silica filled epoxy system. ${ }^{16}$ The silica has been used widely in epoxy integrated circuits encapsulating compounds to reduce the CTE of epoxy. However, the addition of silica usually results in the compound having problems of high viscosity and phase separation. A homogeneous BP/SAA should be a good replacement for silica reinforced material.

Figures 4 and 5 show the TGA thermograms of anhydride cured epoxies and amine cured ep-

Table II List of Coefficients of Thermal Expansion of Amine and Anhydride Cured Epoxies

\begin{tabular}{lcc}
\hline Epoxy Network & $\begin{array}{c}\mathrm{CTE}^{\mathrm{a}}\left(\mu \mathrm{m} / \mathrm{m}^{\circ} \mathrm{C}\right) \\
\alpha_{1}, \text { Below } T_{g}\end{array}$ & $\begin{array}{c}\mathrm{CTE}^{\mathrm{a}}\left(\mu \mathrm{m} / \mathrm{m}^{\circ} \mathrm{C}\right) \\
\alpha_{2}, \text { Above } T_{g}\end{array}$ \\
\hline DGEBA/MCHDA & 756.30 & 1029.41 \\
TMBP/MCHDA & 305.55 & 603.17 \\
BP/MCHDA & 224.14 & 291.67 \\
AM/MCHDA & 225.52 & 310.91 \\
DGEBA/SAA & 137.33 & 515.95 \\
TMBP/SAA & 67.87 & 313.01 \\
BP/SAA & 20.76 & 183.19 \\
AM/SAA & 72.05 & 90.87 \\
\hline
\end{tabular}

${ }^{\text {a }} \mathrm{CTE}$ were measured by TMA, $\alpha_{1}=30^{\circ} \mathrm{C} \sim T_{g}, \alpha_{2}=T_{g}$ $\sim T_{g}+50^{\circ} \mathrm{C}$.

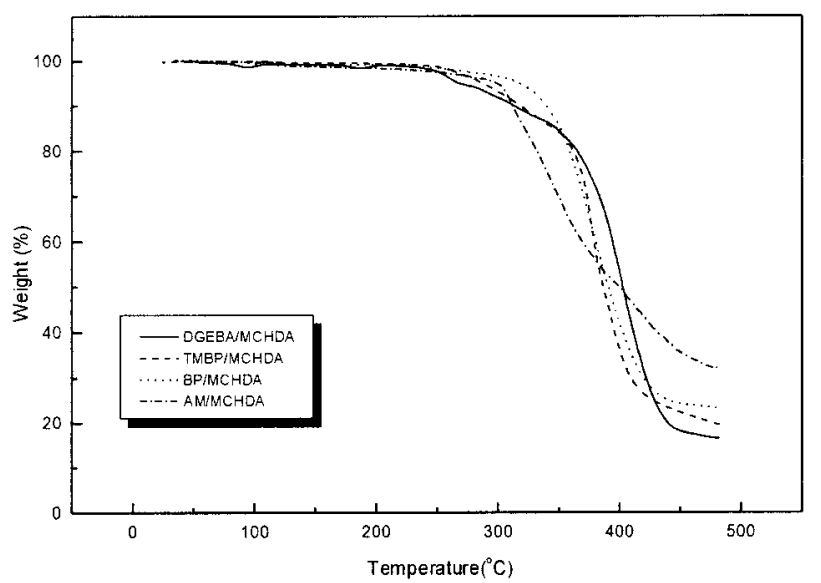

Figure 4 Thermograms of thermal gravimetric analysis of methyl cyclohexane 1,2-dicarboxylic anhydrides cured epoxy resins.

oxies, respectively. The anhydride cured rigid rod epoxies $\mathrm{BP}$ and $\mathrm{AM}$ have a decomposition temperature higher by $30^{\circ} \mathrm{C}$ than that of TMBP and DGEBA, but the amine cured rigid rod epoxies have a decomposition temperature lower by $40^{\circ} \mathrm{C}$ than that of TMBP and DGEBA. Overall weight retention of rigid rod epoxies is higher than that of TMBP and DGEBA regardless the curing agents. The AM/SAA system has shown the highest weight retention of $61 \%$ at $450^{\circ} \mathrm{C}$. The high weight retention behavior could be used in the application of fire retardant material.

By using DSC and polarized microscopy, we observed a smectic liquid crystalline phase in the range of $128-153^{\circ} \mathrm{C}$ for biphenol epoxy and a nematic liquid crystalline phase in the range of

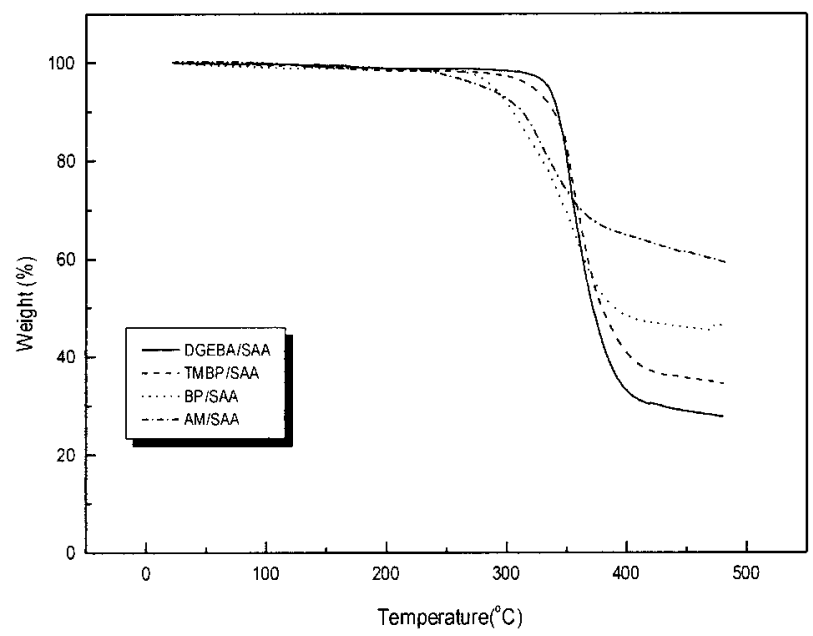

Figure 5 Thermograms of thermal gravimetric analysis of sulfanilamide cured epoxy resins. 


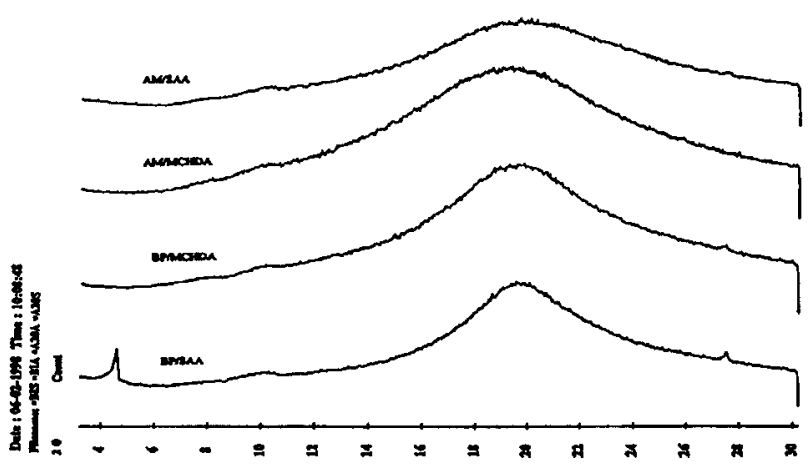

Figure 6 X-ray diffraction patterns of cured rigid rod epoxy resins.

$120-127^{\circ} \mathrm{C}$ for azomethine epoxy. Under the room light, only the BP/SAA sample is opaque; all other seven samples are clear. The opaque feature indicates that there is a crystalline structure in the BP/SAA. An X-ray analysis was performed for rigid rod epoxy system: AM/SAA, AM/MCHDA, $\mathrm{BP} / \mathrm{SAA}$, and BP/MCHDA. Only the BP/SAA has a crystalline structure as shown in Figure 6 . The diffraction peak at $2 \theta=4.37^{\circ}, d$ spacing is equal to $20.2 \AA$ and another diffraction peak at $2 \theta=16$ $\approx 24^{\circ}, d$ spacing is equal to $4 \approx 5 \AA$. Shiota and Ober $^{13}$ reported X-ray study for Twin 8 smectic liquid crystalline epoxy/SAA. They have observed $2 \theta<2^{\circ}, d$ spacing is equal to $43.8 \AA$ and another diffraction peak at $2 \theta=12^{\circ}, d$ spacing is equal to $4.3 \AA$. They assigned their network as a smectic structure. Our value is very close to their value. The uncured BP exhibits a smectic structure. Thus, the smectic structure is possibly preserved in the BP/SAA system. The highly ordered structure of BP/SAA system may be responsible for the lowest CTE value among the samples measured.

\section{CONCLUSIONS}

Ordered rigid rod epoxies: azomethine epoxy, biphenol epoxy, and TMBP have exhibited better thermal and mechanical properties than those of the flexible bisphenol A epoxy. The chemical structures of both rigid rod epoxy and curing agent control the physical properties of cured rigid epoxies. When a flexible curing agent (MCHDA) was used, the chemical structure of rigid rod epoxy has dominated effects. Thus, the AM/MCHDA system shows the best thermal and mechanical properties among three rigid rod epoxy systems. While a rigid curing agent (SAA) was used, the physical properties of cured epoxies are not only dependent on the chemical structure of epoxies but also on the ease of formation of ordered network. Among the cured epoxies, only the biphenol epoxy/SAA exhibits a liquid crystalline network. It has the highest $T_{g}$ of $219^{\circ} \mathrm{C}$ and the lowest coefficient of thermal expansion of 20.8 $\mu \mathrm{m} / \mathrm{m}^{\circ} \mathrm{C}$ in our study. The AM/SAA has the lowest weight loss $(39 \%)$ at $450^{\circ} \mathrm{C}$. The excellent thermal properties of rigid rod epoxies enable them to be used in composites, printed wiring boards, and integrated circuit encapsulations.

The authors thank the National Science Council of Republic of China for supporting this project under Grant NSC87-2216-E-002-004. Dr. L. C. Scala's advice on the preparation of manuscript is highly appreciated.

\section{REFERENCES}

1. Odian, G. Principles of Polymerization, 3rd. ed.; John Wiley \& Sons: New York, 1991; pp.164-167.

2. Donald, A. M.; Windle, A. H. Liquid Crystalline Polymer; Cambridge University: Cambridge, England, 1992.

3. Carfagna, C.; Amendola, E.; Giamberini, M.; Filippov, A.; G. Bauer, R. S. Liq Cryst 1993, 13, 571.

4. Ochi, M.; Tsuyuno, N.; Sakaga, K.; Nakanishi, Y.; Murata, Y. J Appl Polym Sci 1995, 56, 1161.

5. Mormann, W.; Brocher, M. Macromol Chem Phys 1996, 197, 1941.

6. Ochi, M.; Shimizu, Y.; Nakanishi, Y.; Murata, Y. J Polym Sci Part B Polym Phys 1997, 35, 397.

7. Su, W.-F. A. J Polym Sci Part A Polym Chem 1993, $31,3251$.

8. Sue, H. J.; Earls J. D.; Hefner, R. E. Jr. J Mater Sci 1997, 32, 4031-4046.

9. Muller, H. P.; Gipp, R.; Heine, H. U.S. Pat. 4, 764, $581,1988$.

10. Mikroyannidis, J. A. Polym Int 1991, 25, 91.

11. Mikroyannidis, J. A. Makromol Chem 1989, 190, 1867.

12. Mikroyannidis, J. A. J Appl Polym Sci 1990, 41, 2613.

13. Shiota, A.; Ober, C. K. Polymer 1997, 38, 5857.

14. May, C. A.; Tanaka, Y. Epoxy Resins; Marcel Dekker: New York, 1973.

15. Mormann, W.; Brocher, M.; Schwarz, P. Macromol Chem Phys 1997, 198, 3615.

16. Wong, C. P., Ed.; Polymers for Electronic and Photonic Applications; Academic Press: New York, 1993. 